\title{
Omalizumab is effective in the treatment of difficult-to-treat chronic spontaneous urticaria
}

\author{
Jennifer Forgie ${ }^{1 *}$, Stephanie Santucci ${ }^{1}$, Diana Pham ${ }^{1}$, Genevieve Gavigan², Melanie Pratt ${ }^{2}$, Simone Fahim², \\ John O'Quinn', William H. Yang ${ }^{1,3}$ \\ From Canadian Society of Allergy and Clinical Immunology Annual Scientific Meeting 2014 \\ Ottawa, ON, Canada. 23-26 October 2014
}

\section{Background}

Chronic spontaneous urticaria (CSU) is a condition, lasting at least 6 months, where patients experience frequent episodes of red, itchy hives and/or angioedema with no apparent external trigger. For approximately $30-50 \%$ of patients this condition can resolve spontaneously but has been known to persist for years. CSU can have a major impact on a patient's quality of life as it can affect daily activities, sleep, emotional wellbeing and social interactions. In March 2014, omalizumab was approved in Europe and eight other countries for the treatment of CSU in patients with inadequate response to $\mathrm{H}_{1}$-antihistamines at approved doses. However, as yet there is no approved indication for its use in CSU in Canada and the US. We report on the effectiveness of omalizumab as a treatment option for difficult-to-treat CSU in our clinic.

\section{Methods}

After receiving a diagnosis of CSU with inadequate response to $\mathrm{H}_{1}$-antihistamines, and oral prednisone, patients completed a quality of life (QoL) questionnaire prior to beginning treatment with omalizumab. Patients were requested to complete the QoL questionnaires every two weeks throughout the treatment and, in addition, were monitored closely for clinical response.

\section{Results}

A total of 10 patients, who started on omalizumab for $\mathrm{CSU}$ were evaluated. All were taking $\mathrm{H}_{1}$-antihistamines prior to treatment with 8 out of the 10 patients able to decrease or stop the use of $\mathrm{H}_{1}$ - antihistamines after the $3^{\text {rd }}$ dose of omalizumab.

${ }^{1}$ Allergy and Asthma Research Centre, Ottawa, ON, Canada

Full list of author information is available at the end of the article
The results of the questionnaires indicated a $15 \%$ improvement in QoL with an accompanying 18\% decrease in the symptom score. Of the 10 patients, 9 indicated an overall improvement in their symptoms while only 6 had an overall improvement in their QoL.

\section{Conclusion}

Omalizumab is an effective therapy in difficult-to-treat CSU in our tertiary community based allergy and asthma clinic.

\section{Authors' details}

${ }^{1}$ Allergy and Asthma Research Centre, Ottawa, ON, Canada. ${ }^{2}$ Division of Dermatology, University of Ottawa, ON, Canada. ${ }^{3}$ University of Ottawa Medical School, Ottawa, ON, Canada.

Published: 18 December 2014

doi:10.1186/1710-1492-10-S2-A8

Cite this article as: Forgie et al:: Omalizumab is effective in the treatment of difficult-to-treat chronic spontaneous urticaria. Allergy, Asthma and Clinical Immunology 2014 10(Suppl 2):A8.

Submit your next manuscript to BioMed Central and take full advantage of:

- Convenient online submission

- Thorough peer review

- No space constraints or color figure charges

- Immediate publication on acceptance

- Inclusion in PubMed, CAS, Scopus and Google Scholar

- Research which is freely available for redistribution 